\title{
A Case of Bronchial Asthma Complicated by Epidural Emphysema
}

\author{
Takashi Adachi Masahide Oki Shigehisa Kajikawa Hideo Saka \\ Department of Respiratory Medicine, Nagoya Medical Center, Nagoya, Japan
}

A 22-year-old man with an asthma attack was transported by ambulance to our emergency room. He had a past history of asthma but had not received a medical examination regularly. He complained of severe dyspnea, coughing and upper chest pain for several days. On admission, he showed severe hypoxia requiring supplemental oxygen at a rate of 6 liters/min, but no neurological symptoms. Chest computed tomography (CT) showed pneumomediastinum and radiolucent space in the spinal canal suggesting epidural emphysema (fig. 1). He received conservative treatment for bronchial asthma including a corticosteroid and bronchodilator for 3 days, whereupon his symptoms improved. The follow-up CT 7 days later revealed that the air in the epidural space and mediastinum had disappeared.

Epidural emphysema, which shows the presence of air in the spinal epidural space, is a rare entity. Most cases are caused by trauma or iatrogenic interventions, and to the best of our knowledge, only 17 cases associated with bronchial asthma have been reported in the literature up to February 2012. The mechanism by which this condition is considered to develop is the exfoliation of transudative air in the posterior mediastinum space due to high bronchoalveolar pressure, and the subsequent invasion of the epidural space. Epidural emphysema rarely causes neurological symptoms and improves spontaneously with conservative treatment in most cases $[1,2]$.

\section{References}

1 Oertel MF, Korinth MC, Reinges MH, Krings T, Terbeck S, Gilsbach JM: Pathogenesis, diagnosis and management of pneumorrhachis. Eur Spine J 2006;15(suppl 5):636-643.

-2 Aribas OK, Gormus N, Aydogdu Kiresi D: Epidural emphysema associated with primary spontaneous pneumothorax. Eur J Cardiothorac Surg 2001;20:645-646.
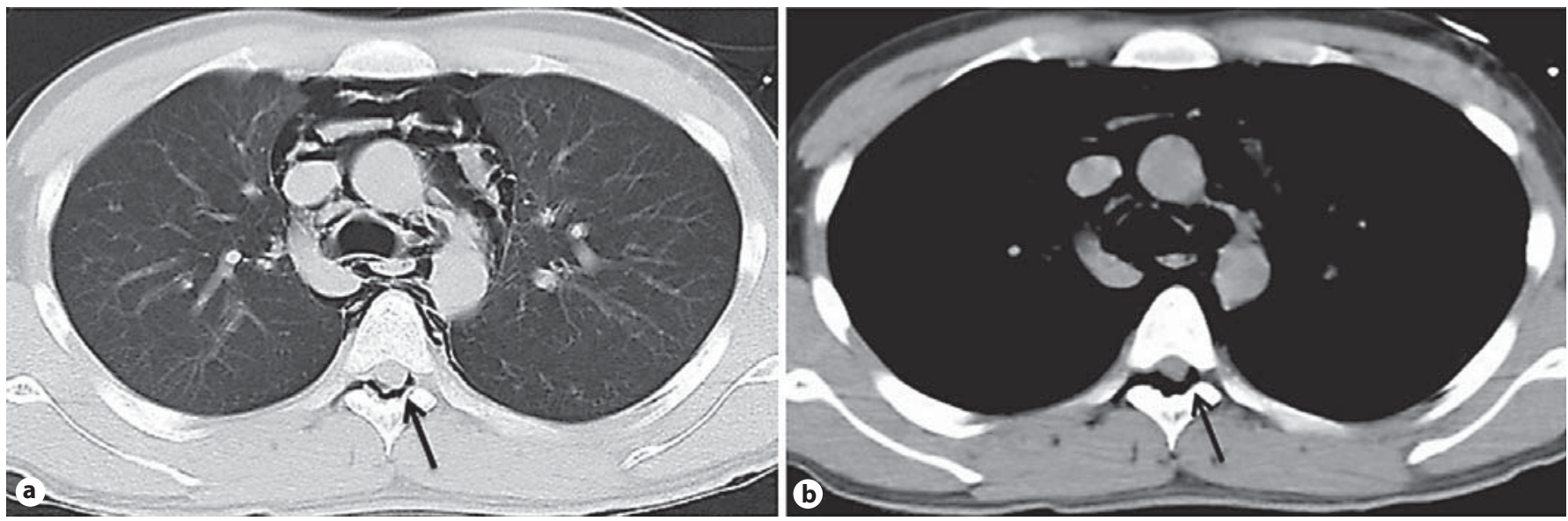

Fig. 1. Chest CT on parenchymal (a) and mediastinal (b) window settings showing air in the spinal epidural space (arrows).

\section{KARGER}

Fax +41613061234

E-Mail karger@karger.ch

www.karger.com
(C) $2012 \mathrm{~S}$. Karger AG, Basel

$0025-7931 / 12 / 0841-0069 \$ 38.00 / 0$

Accessible online at:

www.karger.com/res
Takashi Adachi

Department of Respiratory Medicine, Nagoya Medical Center

4-1-1 Sannomaru, Naka-ku

Nagoya 460-0001 (Japan)

Tel. +81 52951 1111,E-Mail t_adachi@aol.jp 